\title{
Frank hematuria as sole manifestation of acute myeloid leukemia: A case report
}

\author{
ML Patel, Rekha Sachan, Apul Goel
}

\begin{abstract}
Introduction: Unexplained hematuria may be presenting feature of various systemic illnesses such as coagulation disorder, anticoagulation therapy, leukemia, disseminated intravascular coagulation and multiorgan dysfunction. Bleeding is a common presenting feature of acute leukemia. This may occur in any mucosal surface of body. Case Report: A 52-year-old male presented with complaints of low grade fever, and gross hematuria for last three days. He was diagnosed as a case of acute myeloid leukemia on the basis of bone marrow aspiration and cytochemistry. Conclusion: Presentation of acute leukemia with gross hematuria is uncommon. Gross hematuria as the sole presenting feature in such cases is unusual and only few cases have been described in literature.
\end{abstract}

Keywords: Frank hematuria, Acute myeloid leukemia, Chemotherapy, Cystoscopy.

$* * * * * * * * *$

ML Patel, Sachan R, Goel A. Frank hematuria as sole manifestation of acute myeloid leukemia: A case report.

ML Patel ${ }^{1}$, Rekha Sachan ${ }^{2}$, Apul Goel $^{3}$

Affiliations: ${ }^{1} \mathrm{MD}$ (Medicine), Assistant Professor, Department of Medicine, CSM Medical University, Lucknow; ${ }^{2} \mathrm{MS}$ (Obs \& Gynae), Associate Professor, Department of Obstetrics and Gynaecology, CSM Medical University, Lucknow; ${ }^{3} \mathrm{MS}$, MCh (Urology), Professor, Department of Urology, CSM Medical University, Lucknow.

Corresponding Author: Dr. ML Patel, MD, Assistant

Professor, Department of Medicine, CSM Medical University, Lucknow-226003, Uttar Pradesh, India; Tel: +919839007000;

Email: patel.ml66@gmail.com

Received: 21 January 2012

Accepted: 06 May 2012

Published: 01 October 2013
International Journal of Case Reports and Images 2013;4(10):575-577.

$* * * * * * * * *$

doi:10.5348/ijcri-2013-10-383-CR-12

\section{INTRODUCTION}

Usually, frank hematuria is a clinical manifestation of various systemic illnesses such as coagulation disorders, anticoagulation therapy, leukemia, disseminated intravascular coagulation and multiorgan dysfunction (severe liver function derangement) [1]. Hemorrhagic cystitis due to viral infection like Adeno virus, BK/JC virus reported in immunocompromised patients [2]. Acute leukemia particularly acute myeloid leukemia can result in leukemic infiltration of many organs including urinary tract resulting in manifestations like hematuria [1]. Though leukemic infiltration of urinary tract is clinically not evident but autopsy studies have been shown involvement of urinary system [3]. Gross hematuria is an uncommon presentation of acute leukemia. Bleeding in acute leukemias usually results from thrombocytopenia, involving the skin, mucous membrane and may or may not correlate with the degree of thrombocytopenia as platelet dysfunction may also be present. Another cause of bleeding in some patients with acute myeloid leukemia is coagulopathy due to disseminated intravascular coagulation (DIC), which is commonly seen in patients with acute promyelocytic leukemia [4].

\section{CASE REPORT}

A 52-year-old male patient was admitted in Department of Medicine, Chhatrapati Shahuji Maharaj Medical University, (Erstwhile KGMC) Lucknow in January 2011 with complaints of low grade fever, and gross hematuria for last three days. On general examination patient was febrile $100.6^{\circ} \mathrm{F}$, blood pressure $130 / 80 \mathrm{mmHg}$, pulse 
$86 / \mathrm{min}$, mild pallor present and no signs of dehydration was present. General examination revealed there was no lymphadenopathy, icterus, edema, hemorrhagic spot or bleeding from any other site on the body. Systemic examination was within normal limit no palpable lump was present in abdomen. There was no history of intake of medication such as anticoagulation therapy, antiplatelet drug, nonsteroidal anti-inflammatory drug or steroid in the past.

On routine investigation hemoglobin $7.8 \mathrm{~g} / \mathrm{dL}$, leukocyte count $20.6 \times 10^{3} / \mu \mathrm{L}, \mathrm{MCV} 90 \mathrm{fL}, \mathrm{MCH} 30 \mathrm{pg}$, and platelet count was $60.0 \times 10^{3} / \mu \mathrm{L}$. General blood picture revealed $22 \%$ blast cells with auer rods. Liver function tests and coagulation profile were normal. Serum creatinine was $1.2 \mathrm{mg} / \mathrm{dL}$ and blood urea was $24 \mathrm{mg} / \mathrm{dL}$. Mid stream urine examination showed protein in traces, 2-4 pus cells/high power field, and numerous red blood cells along with amorphous deposit of crystals. Urine culture and sensitivity were sterile, there was no evidence of glomerulonephritis. FDP and D-dimer were normal. Patient refused PCR test for detection of viral etiology. Ultrasonography of kidney and computed tomography (CT) scan of abdomen revealed no abnormality of urinary tract region. Cystoscopic examination of the bladder was normal (Figure 1). The bone marrow aspirate and cytochemistry were consistent with the diagnosis of acute myeloid leukemia of $\mathrm{M}_{4} \mathrm{FAB}$ subtype. The patient was kept on induction chemotherapy (daunorubicin 50 $\mathrm{mg} / \mathrm{m}^{2} /$ day on day $1,2,3$ and cytarabine $150 \mathrm{mg} / \mathrm{m}^{2} /$ day, intravenous infusion for seven days) and achieved remission. Hematuria subsided within three days after treatment.

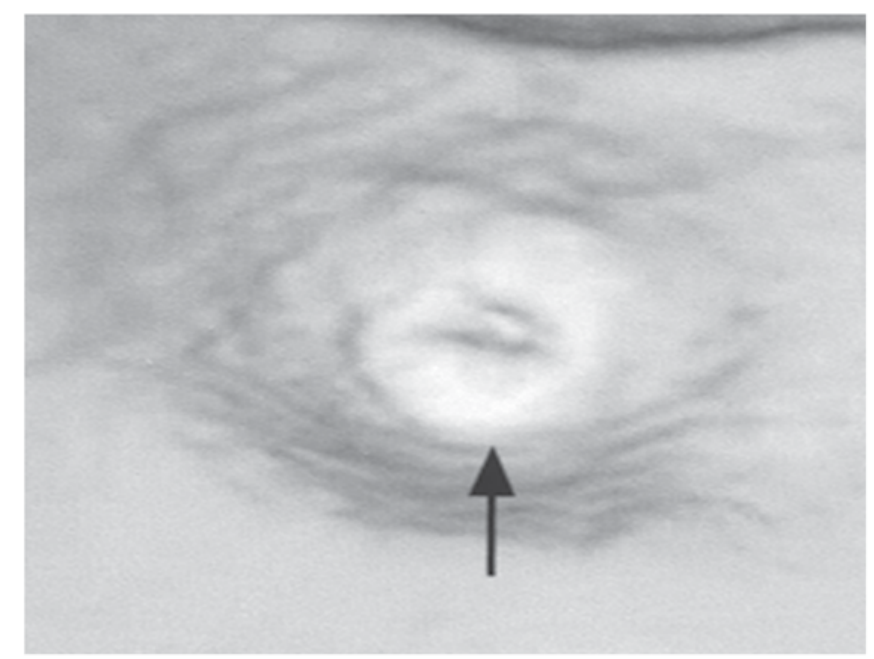

Figure 1: Cystoscopy of urinary bladder of patient showing normal healthy wall and ureteric orifices.

\section{DISCUSSION}

Frank hematuria is a clinical manifestation of various systemic illnesses such as coagulation disorders, anticoagulation therapy, leukemia, disseminated intravascular coagulation and multiorgan dysfunction (severe liver function derangement).

Hematuria as the only or main presenting feature in acute leukemia is rare and to best of our knowledge only 17 cases have been reported till now $[5,6]$. In this case blood investigation reports were suggestive of acute leukemia. Although any organ system in the body can be infiltrated by leukemic cells but involvement of renal system is unusual. If the urinary tract is infiltrated by leukemic cells, kidney is the most common site of involvement [5, 7]. Leukemic infiltration of the urinary bladder is very rare, till date only few cases have been reported [5-8]. In this case though cystoscopy was normal but it could not ruled out occult leukemic infiltration, this could be confirmed only by biopsy but patient refused for the same.

Although clinically evident involvement of the urinary system and hematuria as the presenting symptom is rare, leukemic infiltration was observed in more than 50\% of cases in an autopsy study [7]. Our case was unusual, because patient initially presented with gross hematuria, later on diagnosed as a case of acute myeloid leukemia on the basis of bone marrow aspiration and cytochemistry [9]. However, malignancy of kidney or urinary bladder could be another possible cause of hematuria, as per review based on the articles mentioned bladder cancer usually causes no frank hematuria until it reaches an advance stage. Mainly large exophytic urinary bladder carcinoma causes frank hematuria. In our reported case patient who initially presented with gross hematuria, diagnosed as case of systemic disease (acute myeloid leukemia). In this case since hematuria did not recur after the treatment with chemotherapy for acute myeloid leukemia despite the drop in platelet count to very low level, the possibility of occult leukemic infiltration of urinary tract appears to be the likely cause of hematuria. The disappearance of hematuria also suggests that disease responded with the treatment and this hematuria might be due to acute myeloid leukemia.

Hemorrhagic cystitis due to viral infection like Adeno virus, BK/JC virus usually occurs between 1560 days following bone marrow transplantation and within the first three months of kidney transplantation in immunocompromised patients [9, 10]. Our patient was not immunocompromised so the possibility of hemorrhagic cystitis was ruled out [11].

\section{CONCLUSION}

There are so many causes of hematuria such as viral hemorrhagic cystitis, kidney or urinary bladder malignancy and systemic illness. When patient presented with hematuria as the main symptom, acute leukemia should be kept in mind. 


\section{Acknowledgements}

We acknowledge Dr. Ravi Uniyal, Senior Resident, Department of Medicine, CSMMU, Lucknow for helping in collection of data and investigation.

\section{Author Contributions}

ML Patel - Substantial contributions to conception and design, Acquisition of data, Analysis and interpretation of data, Drafting the article, Revising it critically for important intellectual content, Final approval of the version to be published

Rekha Sachan - Acquisition of data, Revising it critically for important intellectual content, Final approval of the version to be published

Apul Goel - Acquisition of data, Revising it critically for important intellectual content, Final approval of the version to be published

\section{Guarantor}

The corresponding author is the guarantor of submission.

\section{Conflict of Interest}

Authors declare no conflict of interest.

\section{Copyright}

(C) ML Patel et al. 2013; This article is distributed under the terms of Creative Commons attribution 3.0 License which permits unrestricted use, distribution and reproduction in any means provided the original authors and original publisher are properly credited. (Please see www.ijcasereportsandimages.com/copyright-policy.php for more information.)

\section{REFERENCES}

1. Persky L, Newman AJ, Tucker AS. Urologic manifestations of childhood Leukemia. J Urol
1972;107(6):1073-7.

2. David Ghez, Eric Oksenhendler, Catherine Scieux, Kaiss Lassoued. Haemorrhagic cystitis associated with Adenovirus in a patient with AIDS treated for a non-Hodgkin's Lymphoma. American journal of Hematology 2000;63(1):32-4.

3. Vidana E, Bross ID, Pricken JW. An autopsy study of metastatic patterns of human leukemia. Oncology 1978;35(2):87-96.

4. Tallman MS, Kwaan HC. Reassessing the hemostatic disorder associated with acute promyelocytic leukemia. Blood 1992 Feb 1;79(3):543-53.

5. Watson EM, Sauer HR, Sadugor MG. Manifestation of the lymphoblastomas in the genitor-urinary tract. J Urol 1949;61(3):626-45.

6. Chang CY, Chiou TJ, Hsieh YL, Cheng SN. Leukemic infiltration of the urinary bladder presenting as uncontrollable gross hematuria in a child with acute lymphoblastic leukemia. J Pediatr Hematol Oncol 2003 Sep;25(9):735-9.

7. Kirshbaum JD, Preuss FS. Leukemia: a clinical and pathologic study of one hundred and twenty-three fatal cases in a series of 14400 necropsies. Arch Intern Med 1943;71:777.

8. Pentecost CJ, Pizzolato P. involvement of the genitourinary tract in Leukemia. J Urol 1945;53:725.

9. Owais M. Suriya, Aamer Aleem. Frank Hematuria as the Presentation feature of Acute leukemia. Saudi J Kidney Dis Transpl 2010;21(5):940-2.

10. Koga S, Shindo K, Matsuya F, Hori T, Kanda S, Kanetake H. Acute hemorrhagic cystitis caused by adenovirus following renal transplantation: Review of the literature. J Urol 1993;149(4):838-9.

11. Miyamura K, Takeyama K, Kojima S, et al. Hemorrhagic cystitis associated with urinary excretion of adenovirus type 11 following allogeneic bone marrow transplantation. Bone Marrow Transplant 1989;4(5):533-5.
Access full text article on other devices

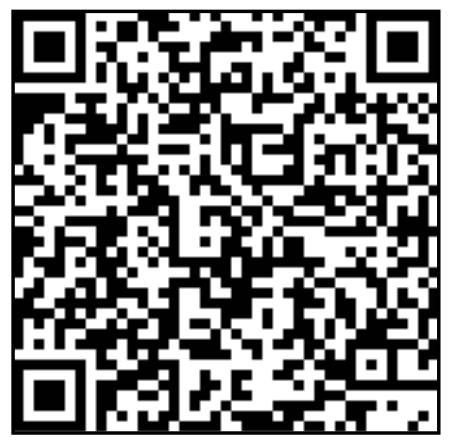

Access PDF of article on other devices

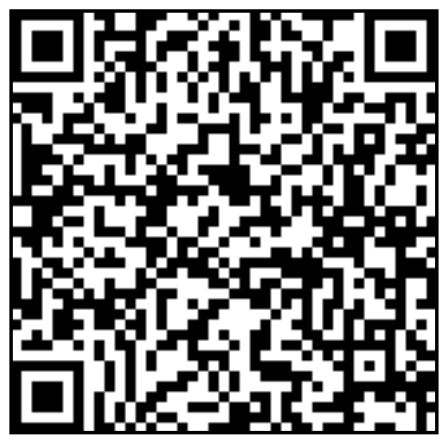

